\title{
A COMPARISON Study BeTWEen THE THERMAL PERFORMANCE OF THE ORIGINAL AND REBUILT VERNACULAR BUILDINGS OF DANA VILLAGE IN JORDAN
}

\author{
Rawan Allouzi*, Nikolaos Karydis, and Marialena Nikolopoulou \\ School of Architecture and Planning, University of Kent, Canterbury, United Kingdom
}

\begin{abstract}
The settlement of Dana in Jordan is undergoing dramatic and rapid changes. The rehabilitation project launched by the Royal Society for the Conservation of Nature (RSCN) provided new tourist accommodation within the settlement, in a way that preserves its unique vernacular character. This has involved the repair and transformation of existing dwellings as well as the rebuilding of those that have been demolished. Currently, the original and rebuilt buildings stand side by side, offering a unique opportunity to compare their thermal performance. This comparison is essential to understand the impact of new construction materials and opening sizes on the thermal performance of vernacular buildings. For this purpose, the thermal performance of rebuilt and original buildings was monitored in August 2019 and February 2020, representing the hot and cold seasons. The recorded data was interpreted statistically, aiming mainly to compare the results from the original rooms with those from the rebuilt rooms. The study showed that the original buildings of Dana hotel resist thermal transfer more than the rebuilt ones. Both parts provided thermal comfort in summer, with the rebuilt rooms offering slightly better thermal comfort conditions. However, neither original nor rebuilt rooms provided adequate thermal comfort in winter.
\end{abstract}

Keywords: Dana village; Original buildings; Rebuilt buildings; Thermal comfort; Thermal performance; Vernacular settlement.

$$
\begin{aligned}
& \text { دراسة مقارنة بين الأداء الحراري لمباني تراثية أصلية، وأخرى معاد بناؤها في قرية ضانا في الأردن } \\
& \text { روان اللوزي"، نيك لاس كاريبيس، ماريالينا نيكولمبوله }
\end{aligned}
$$

الملفص: تمر قرية ضانا في الأردن بتغير ات دراماتيكية وسريعة. وفر مشروع إعادة التأهيل ـ الذي أطلقته الجمعية الملكية

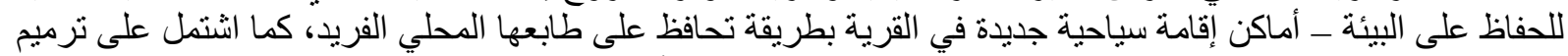

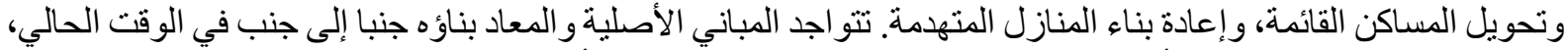

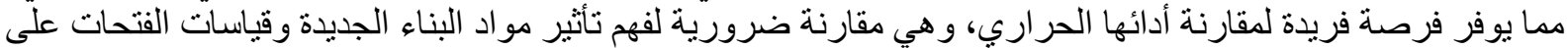

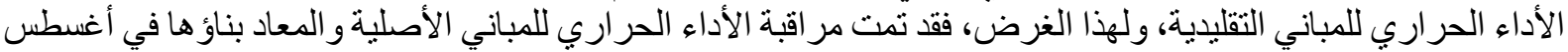

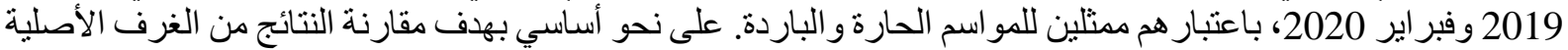

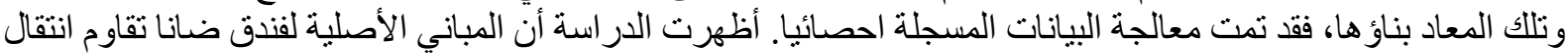

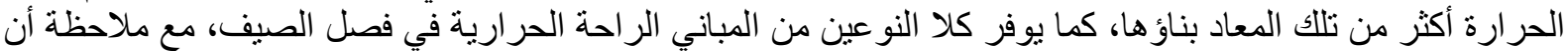

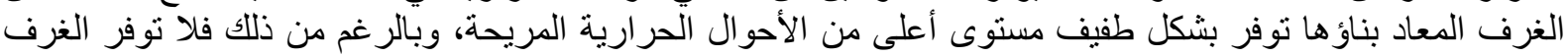

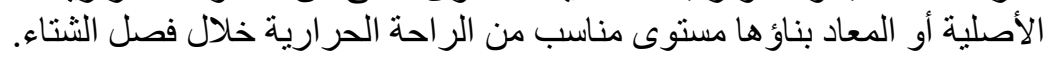

الكلمات المفتاحية: الأداء الحر اري؛ المباني الأصلية؛ المباني المعاد بناؤها؛ الر احة الحرارية؛ قرية تقليدية؛ قرية ضانا. 


\section{NOMENCLATURE}

R-value: Thermal resistance $\left(\mathrm{m}^{2} . \mathrm{K} / \mathrm{W}\right)$

Tair: Air temperature $\left({ }^{\circ} \mathrm{C}\right)$

Tout: Outdoor temperature $\left({ }^{\circ} \mathrm{C}\right)$

U-value: Thermal transmittance $\left(\mathrm{W} / \mathrm{m}^{2} . \mathrm{K}\right)$

\section{INTRODUCTION}

Dana village $\left(30.67^{\circ} \mathrm{N}, 35.61^{\circ} \mathrm{E}\right)$ in Jordan was built between the 1890s and 1930s. Dana was formed of single-story buildings with flat roofs. The organization of contiguous buildings in clusters is one of the main characteristics of the village, looking like one cohesive/compact unit. After the 1960s, the local community of Dana started to move out, looking for better services and job opportunities. By 1996, the village was almost abandoned, and most of its buildings turned into ruins (Figure 1). Therefore, the RSCN launched the rehabilitation project of Dana village in 2009 to restore vernacular dwellings to accommodate tourists and visitors (Al Haija, 2011).

Several restoration strategies were implemented, such as the replacement of the original materials, the transformation of the building envelope, the enlargement of the opening sizes, and the addition of lighting shafts, and bathrooms (Table 1). The implementation of these changes affected the indoor thermal conditions that depend mainly on several factors, including the construction materials, opening sizes, thermal mass, and orientation (Alzoubi \& Almalkawi, 2019; Fernandes et al., 2015; Meier et al., 2004).

Various previous studies discussed the effect of these factors on an individual basis, comparing the thermal performance of traditional and contemporary buildings. For instance, Tawayha et al. (2019) stated that using local and natural materials used in vernacular architecture plays an essential role in improving thermal performance. Weber \& Yannas (2013) and Priya et al. (2012) added that the advantages of using local construction materials in improving the thermal performance of vernacular buildings include the low conductivity of thermal transfer and providing stable indoor thermal conditions. Furthermore, Toe \& Kubota (2015) and Philokyprou \& Michael (2012) stated that the high thermal mass improves the indoor temperature stability, reduces daily fluctuation, and increases the time lag. Indeed, having thicker walls with higher thermal mass adapts vernacular buildings to the hot conditions by reducing exposure to direct solar radiation. Whereas in winter, the small size of openings provides thermal comfort as it allows the direct solar gains and protects the indoor spaces from cold and strong winds (Tawayha et al., 2019). Previously conducted studies presented the impact of transforming the building's envelope on an individual basis, including the construction materials, thermal mass, and opening sizes and orientation (Weber \& Yannas, 2013;
Fernandes et al., 2015; Alzoubi \& Almalkawi, 2019). However, there is a shortage in the study of the total impact of the restoration strategies of vernacular buildings as most studies focused on comparing vernacular and contemporary buildings. Therefore, this paper seeks to assess the effectiveness of the restoration strategies of Dana village by analyzing the thermal performance of both the original and rebuilt vernacular buildings. It aims to identify which type is more effective in providing thermal comfort in summer and winter while highlighting the effect of the restoration on thermal performance. For this purpose, the internal and external conditions of Dana hotel were monitored in August 2019 and February 2020 as representative of the hot and cold season. Dana has a cold climate in winter and a temperate to warm climate in summer (Table 2).
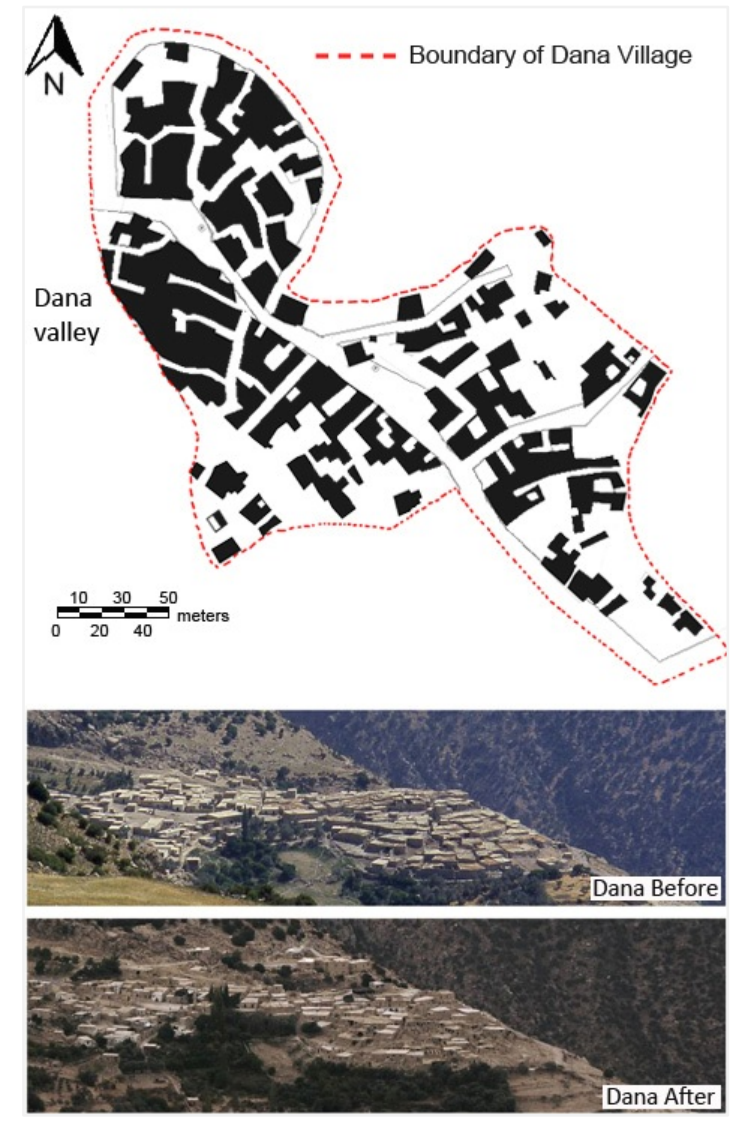

Figure 1. Figure Ground Plan of Dana Village (top), Dana village before (middle) and after abandonment (bottom) (Archive, RSCN, 2019).

Table 1. The original and rebuilt elements of Dana village.

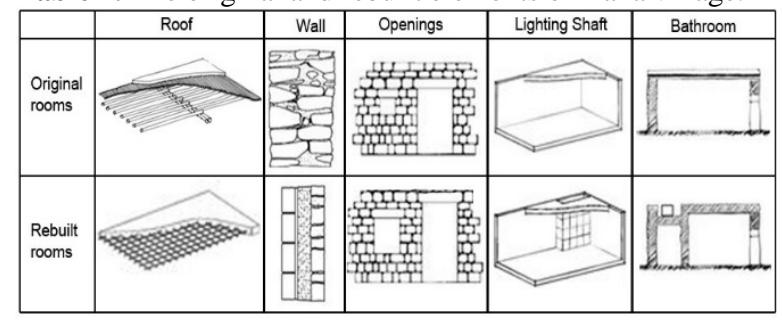


Table 2. Dana monthly air temperature (CLIMATE-DATA.ORG. Retrieved June,21,2020).

\begin{tabular}{ccccccccccccc}
\hline Tair $\left({ }^{\circ} \mathrm{C}\right)$ & Jan & Feb & Mar & Apr & May & June & July & Aug & Sep & Oct & Nov & Dec \\
\hline Avg & 5.6 & 6.6 & 9.6 & 13.2 & 16.5 & 19.6 & 21.1 & 21.7 & 19.4 & 16.7 & 11.7 & 7.4 \\
\hline Min & 1.5 & 1.8 & 4.3 & 7.4 & 10.2 & 12.6 & 14.6 & 15.2 & 12.7 & 10.4 & 6.5 & 2.7 \\
Max & 9.8 & 11.4 & 14.9 & 19.1 & 22.9 & 26.7 & 27.7 & 28.3 & 26.2 & 23 & 17 & 12.2 \\
\hline
\end{tabular}

Table 3. Thermal properties of the original and new materials (Alzoubi \& Almalkawi, 2019, adapted by the author, 2020)

\begin{tabular}{|c|c|c|c|c|c|c|c|c|c|c|}
\hline & \multicolumn{5}{|c|}{ Original part } & \multicolumn{5}{|c|}{ Rebuilt part } \\
\hline & 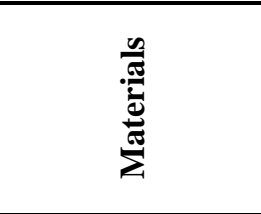 & 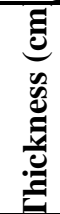 & 园 & 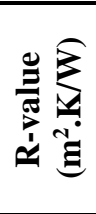 & 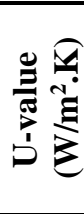 & 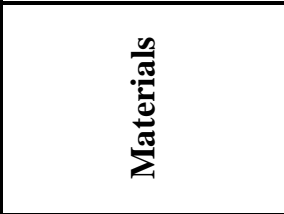 & 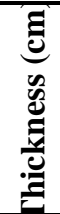 & 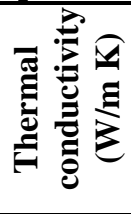 & 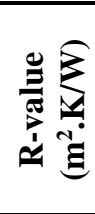 & 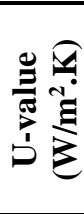 \\
\hline \multirow{4}{*}{ 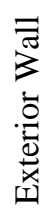 } & Stone & 70 & 5 & 0.14 & \multirow{4}{*}{ مิ } & Stone & 20 & 5 & 0.040 & \multirow{4}{*}{ 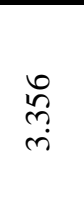 } \\
\hline & \multirow{3}{*}{$\begin{array}{c}\text { A mixture of clay } \\
\text { and straw }\end{array}$} & \multirow{3}{*}{10} & \multirow{3}{*}{0.16} & \multirow{3}{*}{0.625} & & Concrete & 10 & 1.7 & 0.059 & \\
\hline & & & & & & $\begin{array}{c}\text { Hollow concrete } \\
\text { block }\end{array}$ & 15 & 0.833 & 0.180 & \\
\hline & & & & & & Cement plaster & 2.5 & 1.3 & 0.019 & \\
\hline \multirow{7}{*}{ 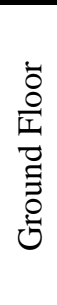 } & Earth & 50 & 1.4 & 0.357 & \multirow{7}{*}{$\begin{array}{l}\hat{\theta} \\
\text { ṃ. } \\
0\end{array}$} & Earth & 50 & 1.4 & 0.357 & \multirow{7}{*}{ ஓ̆ } \\
\hline & Gravel jeer & 45 & 0.38 & 1.184 & & Base-course stone & 15 & 1.5 & 0.10 & \\
\hline & \multirow{2}{*}{ Base course stone } & \multirow{2}{*}{10} & \multirow{2}{*}{1.51} & \multirow{2}{*}{0.066} & & Asphalt insulation & 5 & 1.2 & 0.042 & \\
\hline & & & & & & Reinforced concrete & 10 & 1.28 & 0.078 & \\
\hline & Sand & 45 & 0.42 & 1.071 & & Sand & 10 & 0.40 & 0.25 & \\
\hline & Cement mortar & 2.5 & 0.931 & 0.027 & & Cement mortar & 2.5 & 0.39 & 0.064 & \\
\hline & Terrazzo tile & 2.5 & 1.2 & 0.021 & & Terrazzo tile & 2.5 & 1.20 & 0.021 & \\
\hline \multirow{5}{*}{8} & Juniper wood & 5 & 0.17 & 0.294 & \multirow{5}{*}{ 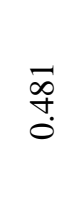 } & Cement mortar & 2.5 & 0.93 & 0.027 & \multirow{5}{*}{$\begin{array}{l}\stackrel{\hat{D}}{N} \\
\text { ले }\end{array}$} \\
\hline & Cane & 3 & 0.056 & 0.536 & & Concrete & 15 & 1.7 & 0.088 & \\
\hline & \multirow{3}{*}{$\begin{array}{c}\text { A mixture of clay } \\
\text { and straw }\end{array}$} & \multirow{3}{*}{20} & \multirow{3}{*}{0.16} & \multirow{3}{*}{1.25} & & Asphalt insulation & 2 & 1.2 & 0.017 & \\
\hline & & & & & & Reinforced concrete & 20 & 1.28 & 0.156 & \\
\hline & & & & & & Cement plaster & 2.5 & 1.3 & 0.019 & \\
\hline
\end{tabular}

\section{DANA HOTEL}

Dana hotel, established in the late 1980s, was selected as a representative case study of Dana village as it consists of both original and rebuilt rooms. The original part of Dana hotel is formed of 12 single-story rooms, surrounding the central courtyard from three sides. It is built mainly of stone, juniper wood, cane, and a mixture of clay and straw. On the other hand, the rebuilt part of Dana hotel is formed of 6 en-suite hotel rooms composed of a bedroom, bathroom, lighting shaft, and kitchenette (Figure 2). It is built mainly of stone, concrete, hollow concrete block, and cement mortar. The use of new construction materials led to having different thermal properties between the original and new building envelope. The thermal properties of both building envelopes are shown in Table 3. The calculated U-Values highlighted that the building envelope of the original part of Dana hotel resists thermal transfer more than the rebuilt part.

\section{METHODOLOGY}

To practically assess the thermal performance of Dana hotel, 10 rooms were monitored for two months in Au gust 2019 and January 2020, including 6 original rooms and4 rebuilt rooms (Figure 2).
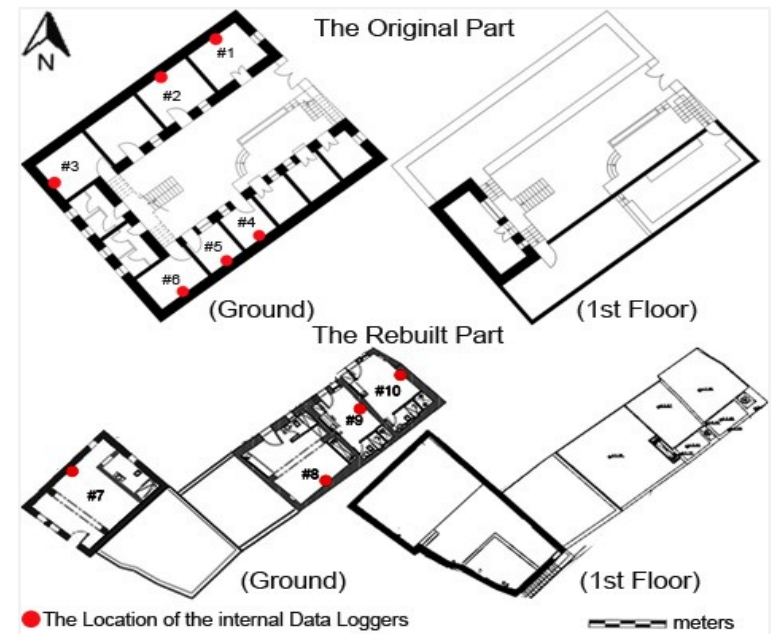

Figure 2. The original and rebuilt part of Dana hotel with logger positions (Archive, RSCN, 2019).

Tinytag loggers were used to record air temperature and relative humidity every 15 minutes, placed at 1.5 $\mathrm{m}$ above the floor level. The collected data was analyzed and compared between the original and rebuilt rooms, demonstrating the variation of the indoor temperatures throughout the day and providing thermal comfort as the criteria of assessment of this study. 
These criteria of assessment were first analyzed within the original and rebuilt part of Dana hotel separately. The statistical method was used to analyze the monitored physical variables to assess the thermal performance. It illustrated the fluctuation of the recorded data (air temperature) throughout the day, from day to day, and from room to room. In addition, thermal comfort was investigated through the adaptive thermal comfort standards BSEN15251 (Nicol et al., 2012). Then, a comparison study was conducted between the final results of both parts, using it as an evaluation method to assess the transformation of Dana's original vernacular buildings within the thermal context.

\section{RESULTS}

\subsection{Thermal Environment}

\subsubsection{Air temperatures in the original rooms}

The mean indoor temperature of the original spaces was always higher than the mean outdoor temperature in summer and winter (Table 4). A typical week of the fluctuation of air temperatures in the different spaces in the different seasons is illustrated in Figure 3. In summer, indoor temperatures followed the outdoor temperature profile but with a significant time lag. More specifically, the indoor temperature was low at night, dropping in the early morning to the minimum and then rising rapidly until the afternoon, when reaching the maximum temperature. However, the maximum temperature was always less than the outdoor temperature around noon due to the thermal mass in all spaces except in the kitchen (space \#6), which is assumed to be from the high internal heat gains from cooking. The high thermal mass of the original masonry thick walls decreased heat transfer to indoor spaces, preventing heat from reaching indoors in the afternoon, which is the hottest part of the day, reaching $36^{\circ} \mathrm{C}$. The high thermal mass demonstrates a thermal lag of 14 hours. Therefore, the night-time temperature difference between indoor and outdoor, which sometimes approaches $10^{\circ} \mathrm{C}$, was more than during the day. Furthermore, the daily variation was noticeable in some spaces more than others due to different functions and occupancy times. Small variation and less significant fluctuation over the day were noticed in rooms $\# 1, \# 3$, \#4, and \#5. This is because the thermal inertia of the thick stone walls and clay roofs offered small fluctuations in the indoor temperature. The high thermal inertia of the original materials increased their capacity to store heat and then emitted it outdoors when the temperature is lower while a small percentage was emitted indoors.
However, lower indoor temperatures were noticed in rooms \#4 and \#5 because their roof is not exposed to the outdoor conditions, having an additional floor at their side. Meanwhile, the roof of rooms \#1 and \#3 is exposed to outdoor conditions and solar radiation, leading to absorbed heat being transferred to indoor spaces.

On the other hand, the diurnal swing values at rooms \#2 and \#6 were more significant and variable, ranging from $4^{\circ} \mathrm{C}$ to $9.7^{\circ} \mathrm{C}$. For room \#6, being used as a kitchen explained the excessive indoor temperature that rose above the outdoor temperature most of the time due to cooking's produced heat. Therefore, the kitchen showed the same fluctuation and temperatures of rooms \#4 and \#5 when it was out of service for maintenance. Furthermore, the absence of windows also raised the indoor temperature, storing the heat indoors without efficient airflow and ventilation. Whereas for room \#2, it was observed that its roof was replaced with a concrete one. Having its roof transformed among the other original spaces created a difference in the thermal performance. The new concrete roof failed to resist heat transfer due to its lower capacity to resist heat transfer than the original clay roofs. Therefore, the indoor temperature of room \#2 showed more fluctuation, reaching higher points compared with the other original hotel rooms.

A different pattern of variations was noticed in winter with lower temperatures. The indoor temperature followed the profile of the outdoor temperature in room \#3, being the coldest room among the other original rooms. Its indoor temperature was either lower than the warm outdoor conditions or close to the cold outdoor conditions. Specifically, the indoor temperature did not increase with higher outdoor temperature but decreased with lower outdoor temperature. This is because the sun does not enter this room due to the absence of windows. Moreover, it showed less variation in temperatures as it was observed that it was not occupied during the winter monitoring period, and the hotel operators confirmed that. Similarly, rooms \#6 and \#4 were also unoccupied but showed higher temperatures due to reduced heat losses from their roof, which is not exposed to the cold outdoor conditions. Room \#1 had similar thermal behaviour to room \#3 until it started being occupied as it is assumed that higher fluctuation appears during occupation due to the internal heat gains from occupants. It showed warmer conditions in the morning due to the eastern window that brings the sunrays indoors. However, still have small values of diurnal swing that vary from $0.1^{\circ} \mathrm{C}$ to $3^{\circ} \mathrm{C}$.

Table 4. Indoor air temperatures $\left({ }^{\circ} \mathrm{C}\right)$ in the original rooms.

\begin{tabular}{c|cc|cc|cc|cc|cc|cc|cc}
\hline & \multicolumn{2}{|c|}{ Tout } & \multicolumn{2}{c|}{ Room \#1 } & \multicolumn{2}{c|}{ Room \#2 } & \multicolumn{2}{c|}{ Room \#3 } & \multicolumn{2}{c|}{ Room \#4 } & \multicolumn{2}{c|}{ Room \#5 } & \multicolumn{2}{c}{ Room \#6 } \\
\cline { 2 - 31 } & Jan & Aug & Jan & Aug & Jan & Aug & Jan & Aug & Jan & Aug & Jan & Aug & Jan & Aug \\
\hline Mean & 6.1 & 24.7 & 7.6 & 26 & 9.7 & 26.6 & 5.6 & 27 & 7.9 & 24.9 & 6.1 & 24.8 & 7.7 & 27.5 \\
\hline Min. & -0.9 & 16.3 & 4 & 23.4 & 5.4 & 22.6 & 2.1 & 24.6 & 6.7 & 21.9 & 2.4 & 21.7 & 5.6 & 23.3 \\
\hline Max. & 20.4 & 36.5 & 11.5 & 29.2 & 16.8 & 33.8 & 9.7 & 29.8 & 9.8 & 27.2 & 10.2 & 27.2 & 10.3 & 35 \\
\hline
\end{tabular}




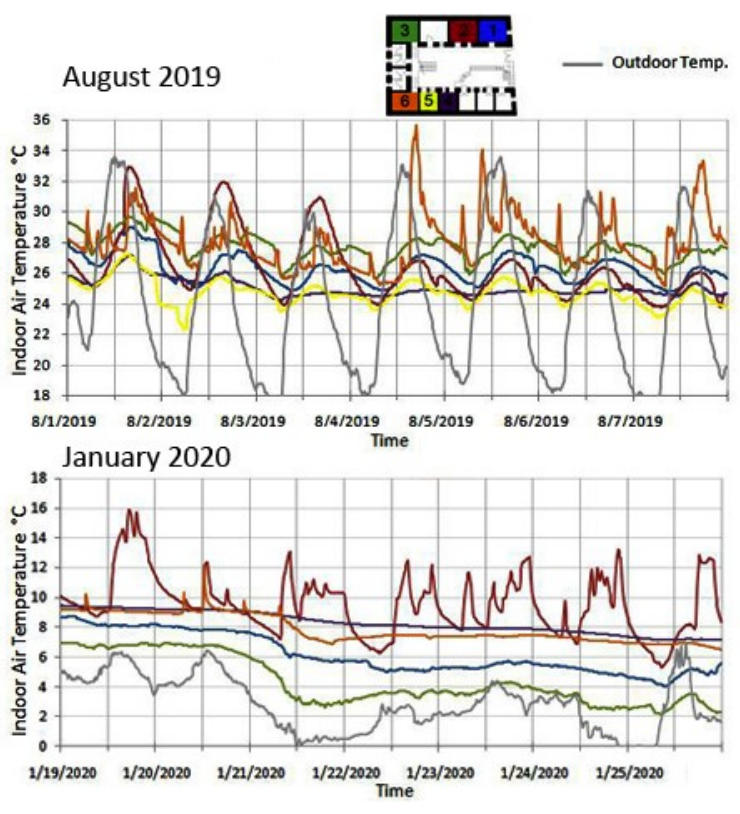

Figure 3. Variation of indoor air temperature in the original rooms in a typical week in summer (top) and winter (bottom).

On the other hand, the daily variation was more noticeable in room \#2, with diurnal swing ranging between $2.4^{\circ} \mathrm{C}$ and $8^{\circ} \mathrm{C}$. The indoor temperature was, most of the time, higher than the outdoor temperature The difference between the outdoor and indoor temperature sometimes approached $12^{\circ} \mathrm{C}$ when the outdoor temperature was cold, reaching $-0.9^{\circ} \mathrm{C}$. The indoor temperature reached its maximum in the afternoon and minimum at midnight. This is because when the outdoor temperature reached its maximum near noon, the concrete roof of room \#2 transferred the absorbed heat to the indoor space after a short time due to its lower thermal capacity. As expected, the variation of indoor temperature was influenced by the building envelope and opening sizes and orientation, as well as construction materials. The few and small size of windows protected the indoor spaces from direct sun rays during summer days and offered good ventilation and cooling at night. Meanwhile, these windows allowed solar gain to indoor spaces during winter days due to their lower elevation angle.

\subsubsection{Air temperatures in the rebuilt rooms}

The mean indoor temperature of the rebuilt spaces was close to the average outdoor temperature in summer, while it was always higher in winter (Table 5). A typical week of the fluctuation of air temperatures in the different spaces in the different seasons is illustrated in Figure 4. In summer, the trend of the indoor and outdoor temperature was different than the original rooms as the changes in the indoor temperature did not follow the changes in the outdoor temperature. Specifically, the indoor temperature was higher than the outdoor temperature at night and lower during the day. The fluctuation of the indoor temperature was small, and the temperature was consistent. Indeed, the daily variation was not noticeable in all spaces despite

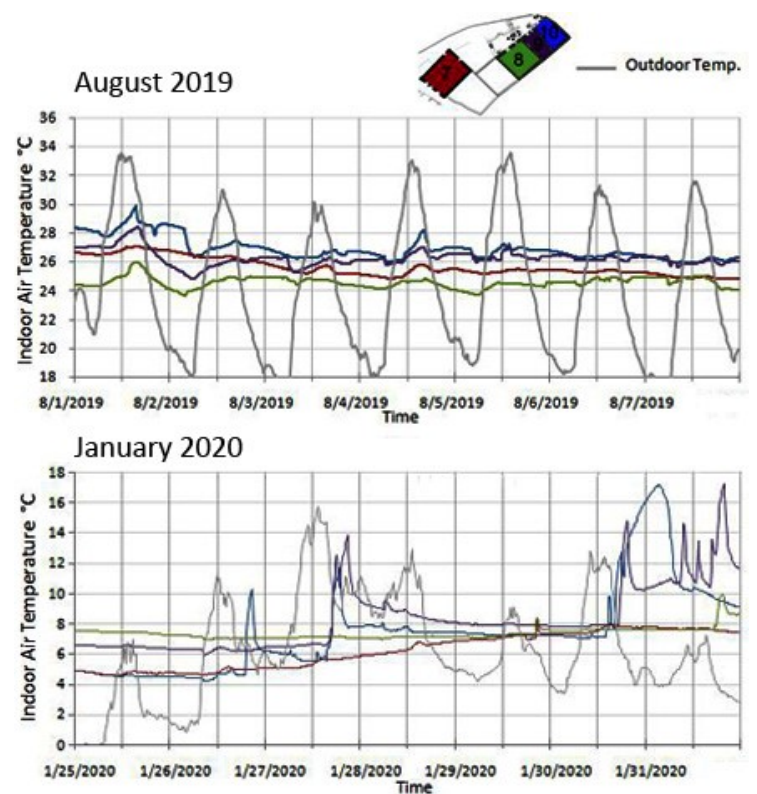

Figure 4. Variation of indoor air temperature in the rebuilt rooms in a typical week in summer (top) and winter (bottom).

different occupancy hours as it was observed that tourists spent their daytime touring the village and its neighbouring areas. They reached the maximum temperature in the afternoon and the minimum in the morning. They provided cooler indoor temperatures when it was the warmest outside and warmer indoor conditions when it was the coldest outside.

The enlargement of windows and the addition of lighting shafts helped in providing cooler conditions. In terms of enlarging the external windows, these windows enhanced air movement due to their bigger size. This strategy was efficient as they are northern windows, which do not bring in solar gains. Moreover, the addition of lighting shafts provided internal windows that enhanced the air movement and ventilation for cooling. Although room \#7 does not have a lighting shaft, it provided cool conditions due to having three windows compared with one window in the other rooms. It was also observed that room \#8 had slightly colder conditions compared with room \#9 and room \#10, although they have the same building envelope, opening size, and orientation. This is because room \#8 is bigger, increasing the heat transfer area in the room. Moreover, room \#7 and room \#8 have approximately the same area, but room \#7 was slightly warmer due to having southwestern windows that bring in solar gains, warming up the indoor spaces in the afternoon.

Table 5. Indoor air temperatures $\left({ }^{\circ} \mathrm{C}\right)$ in the rebuilt rooms.

\begin{tabular}{ccccc} 
Tout & Room & Room & Room & Room \\
& $\# 7$ & $\# 8$ & $\# 9$ & $\# 10$ \\
\hline
\end{tabular}

Jan Aug Jan Aug Jan Aug Jan Aug Jan Aug

$\begin{array}{lllllllllll}\text { Mean } & 6.1 & 24.7 & 7.1 & 25.2 & 9.4 & 24.2 & 8.8 & 25.8 & 7.4 & 26.3\end{array}$

$\begin{array}{lllllllllll}\text { Min. } & -0.9 & 16.3 & 4.5 & 23.6 & 6.9 & 22.5 & 5.9 & 23 & 4.2 & 23.6\end{array}$

\begin{tabular}{llllllllll} 
Max. 20.4 & 36.5 & 9.9 & 27.1 & 13.7 & 26 & 16.5 & 28.3 & 17 & 29.7 \\
\hline
\end{tabular} 
A different pattern was noticed in winter with wider fluctuation, less affected by the changes of the outdoor temperature. Overall, the indoor temperature was higher than the outdoor temperature most of the time. Moreover, the daily variation was noticeable sometimes in some spaces more than others. For instance, the diurnal swing varied from $0.1^{\circ} \mathrm{C}$ to $8.7^{\circ} \mathrm{C}$, showing small values at room \#7 due to non-occupancy status. Meanwhile, the diurnal swing values at rooms \#8, \#9, and \#10 were bigger and more variable according to their occupancy time.

\subsubsection{Comparison between temperatures in the original and rebuilt rooms}

The pattern of the indoor temperature variation was different in the original and rebuilt rooms of Dana hotel. In the summer, indoor temperatures were higher in the original rooms compared with the rebuilt rooms. The indoor temperature was more steady in the rebuilt rooms, showing less variation. On the other hand, the original spaces performed differently, as some spaces such as \#2 and \#6 showed more variation compared with the other original spaces. The more extreme values were noticed in the original spaces. However, they were closer to the mean value in the rebuilt spaces. In winter, the indoor temperatures were either similar in both properties and slightly warmer in the rebuilt rooms. Moreover, the original spaces showed different performance as some rooms such as \#4 and \#6 show less variation in the indoor temperature compared with the other original spaces as they were unoccupied at that time. Meanwhile, the other original and rebuilt spaces provided almost the same variations in the indoor temperature (Figure 5).

The analysis highlighted that performance is greatly affected by the materials of the building envelope, opening sizes and orientation. The external walls of the original rooms are thicker with higher thermal storage compared to the walls of the rebuilt rooms, improving the resistance to heat gain in summer and heat loss in winter. Moreover, the original rooms of Dana hotel have small openings to reduce the climatic influence on the indoor thermal conditions. Along with the thick walls, they prevent solar gains in summer, limit the heat gains and losses, and benefit from night ventilation and wind breeze to cool down indoor spaces. Meanwhile, it reduces heat loss and allows solar gains in winter Figure 6).

On the other hand, the addition of lighting shafts and the enlargement of northern windows adapt the rebuilt rooms to the outdoor conditions in summer. Bigger and more windows were used in the rebuilt rooms, enhancing air movement while preventing solar gains. The orientation of these openings reduced the impact of their size because the direct solar gain is the main contributor affecting the indoor temperature. Therefore, the inward and northern orientation of the windows and lighting shafts of the rebuilt rooms reduce the impact of being more exposed in summer.
Moreover, passive cooling strategies, such as plants and trees in front of the rebuilt rooms, enhance night cool breezes. The adopted changes in the rebuilt rooms worked together to adapt to Dana's weather as a whole system, including the replacement of the building envelope, the addition of lighting shafts, and the enlargement of northern windows. Replacing the building envelope without increasing the opening sizes would disable the whole system, as observed in room \#2. The replacement of the original roof while keeping the original opening sizes failed to adapt to the outdoor conditions, providing more variation in the indoor temperatures.

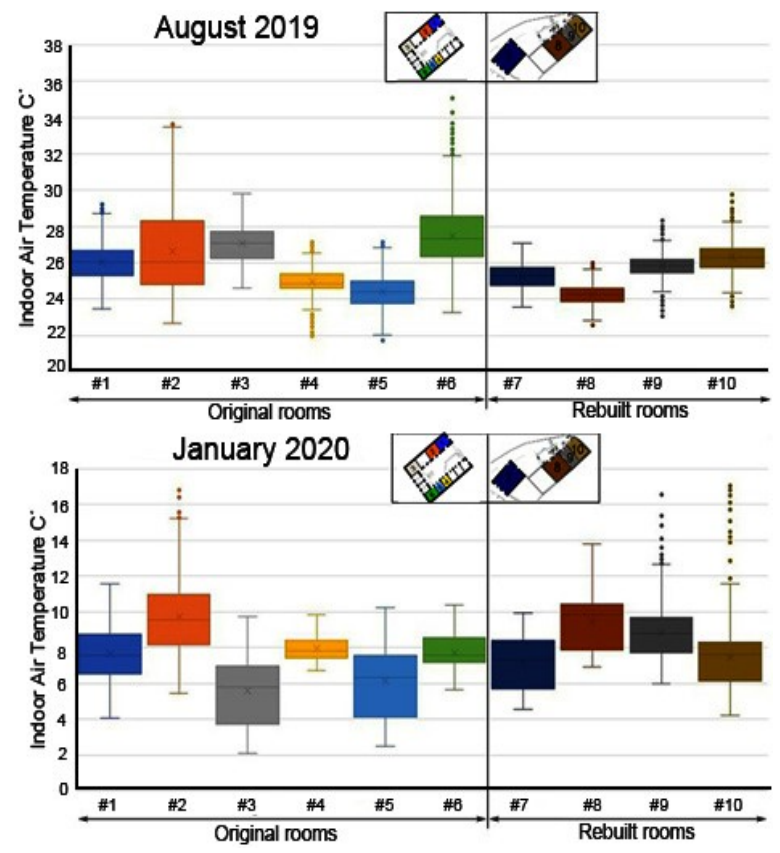

Figure 5. Box plot that shows the mean, extreme, and outlier values of indoor air temperature at each space in the original and rebuilt part of the hotel in summer (top) and winter (bottom).

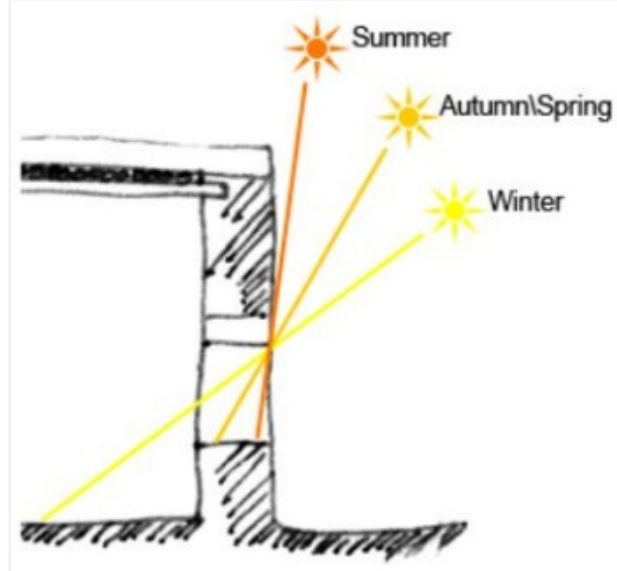

Figure 6. The role of the small size of windows in allowing solar gains in winter and preventing summer's ones. 


\subsection{Thermal Comfort}

\subsubsection{Thermal comfort in the original rooms}

In summer, the daily mean indoor temperatures were entirely within the calculated ranges of comfort temperatures. The large area of the central courtyard plays a significant role in enhancing the efficiency of the original rooms in providing thermal comfort. The courtyard cools down the indoor temperature in summer as it is shaded by the surrounding walls, preventing the sunrays from warming up the rooms. Moreover, the addition of plants, pergolas, and trees also helps provide shading and cooling by evaporation from the plants' green leaves. Overall, $100 \%$ of the mean indoor temperature lay within the comfort ranges; most daily mean indoor temperatures lay within the comfort range of category I, while others lay within the other two categories. Thus, desired thermal comfort was achieved in the original rooms in summer. In winter, however, $100 \%$ of the daily mean indoor temperatures lay outside the three categories of comfort, showing that the daily mean indoor temperature was significantly below comfort temperatures, suggesting that occupants would be in cold discomfort. Thus, all the original rooms showed failure in providing thermal comfort in winter Figure 7).

\subsubsection{Thermal comfort in the rebuilt rooms}

In summer, $100 \%$ of the mean indoor temperature lay within the comfort ranges; most daily mean indoor temperatures lay within the comfort range of category I, while others lay within category II. Thus, thermal comfort was achieved in the rebuilt rooms in summer. In winter, $100 \%$ of the daily mean indoor temperatures also lay outside the three categories of comfort, suggesting that occupants would be in cold discomfort. Thus, all the rebuilt rooms showed a failure to provide thermal comfort in winter Figure 8).

\subsubsection{Comparison between thermal comfort at the original and rebuilt rooms}

Starting with the summer, both the original and rebuilt rooms provided thermal comfort. However, the rebuilt rooms offered slightly better thermal comfort avoiding the higher indoor temperatures. In addition to the passive cooling strategies discussed in both the original and rebuilt rooms, the urban pattern of Dana village played an essential role in providing thermal comfort, showing how the original occupants adapted their houses to the climatic conditions (warm summer and cold winter). The original houses were attached, sharing partition walls. This layout is useful in regions with hot and cold climatic conditions, as it minimizes the exposure of the building envelope to the outdoor environment, which consequently reduces heat transfer (Bodach et al., 2014; Philokyprou et al., 2017).

This urban pattern also features open spaces, including streets and private courtyards that are well relatively small and well-enclosed. In this arrangement, the external walls are less exposed to the outdoor climatic conditions, increasing the building envelope’s thermal insulation.
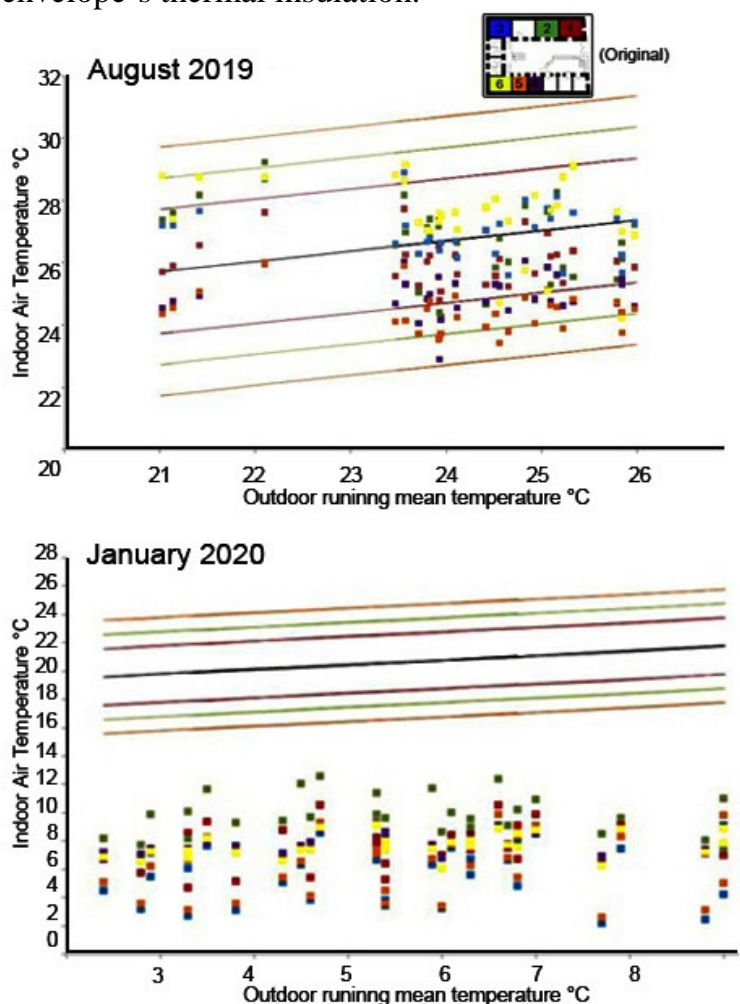

Figure 7. Scatter diagram of the mean indoor temperature within the comfort temperature ranges for the original rooms in summer (top) and winter (bottom).
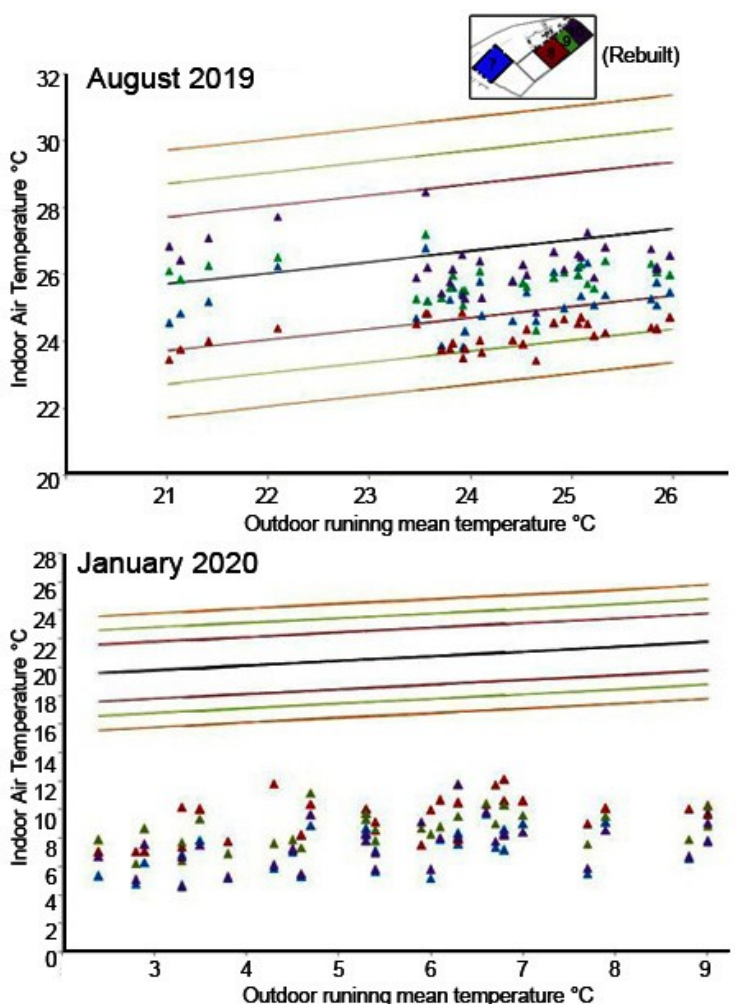

Figure 8. Scatter diagram of the mean indoor temperature within the comfort temperature ranges for the rebuilt rooms in summer (top) and winter (bottom). 
A Comparison Study between the Thermal Performance of the Original and Rebuilt Vernacular Buildings of Dana Village in Jordan

Table 6. The results of comparing the thermal conditions of the original and rebuilt rooms in summer and winter.

\begin{tabular}{|l|c|c|c|c|}
\hline \multirow{2}{*}{} & \multicolumn{2}{|c|}{ Oummer } & \multicolumn{2}{c|}{ Winter } \\
\cline { 2 - 5 } & Original & Rebuilt & Original & Rebuilt \\
\hline Temperature & Higher & Lower Temperature & Almost the Same & Almost the Same \\
\hline Diurnal Swing & Higher & Lower & Almost the Same & Almost the Same \\
\hline Decrement Value & $\begin{array}{c}\text { Provide Thermal } \\
\text { Comfort }\end{array}$ & $\begin{array}{c}\text { Provide Slightly Better } \\
\text { Thermal Comfort }\end{array}$ & $\begin{array}{c}\text { Do not Provide } \\
\text { Thermal Comfort }\end{array}$ & $\begin{array}{c}\text { Almost the Same } \\
\text { Thermal Comide }\end{array}$ \\
\hline Thermal Comfort & \multicolumn{3}{|r}{}
\end{tabular}

Philokyprou et al. (2013) stated that due to narrow streets and spaces between houses, the neighbouring houses shade each other and reduce the heat gain through walls by radiation. On the other hand, both the original and rebuilt rooms did not provide thermal comfort in winter. Indeed, their daily mean indoor temperatures were very low, lying entirely outside the comfort ranges. The analysis of the thermal performance of the original and rebuilt rooms showed that the RSCN was more concerned about providing thermal comfort in the summer months because Dana is a summer tourist destination. Focus on the summer is also because winters in the region are normally shorter than summers.

\section{DISCUSSION AND CONCLUSION}

The thermal performance of the vernacular buildings of Dana demonstrated that the passive and heavyweight buildings, free-running with no heating or cooling systems, can provide thermal comfort during the summer. Singh et al. (2010), Abdel Hadi (2013), Philokyprou et al. (2013), Weber \& Yannas (2013), and Tawayha et al. (2019) demonstrated that the thermal performance of vernacular buildings is generally better than contemporary buildings due to their construction materials and techniques. Therefore, as the rebuilt rooms are built of contemporary materials, the thermal properties of the building envelope were determined by the materials of the external walls, floor, roof, and thickness. The calculated U-values showed that the building envelope of the original rooms of Dana hotel resisted heat transfer better than the rebuilt rooms, confirming the results of the previous studies. However, along with the materials, the building design also influences the resulting indoor conditions, including the opening sizes and orientation (Fernandes et al., 2015). Therefore, monitoring the internal thermal conditions was conducted to show the total impact of the building design.

The results showed that the rebuilt rooms provided stable indoor temperatures, although they do not provide the same thermal mass due to the effect of opening sizes and orientation. This highlighted that although the new construction materials provide higher U-values and less thermal resistance, the rebuilt rooms provided lower temperatures with a lower diurnal swing in summer, contradicting previous studies. Overall, the analysis from the monitoring conducted showed different behaviour between the original and rebuilt part of Dana hotel in summer, while similar behaviour was noticed in winter (Table 6). It highlighted that the indoor temperatures were higher in the original rooms, showing more variations in summer. Furthermore, both the original and rebuilt rooms provided thermal comfort in summer, with the rebuilt rooms offering slightly better comfort. This research could be expanded by conducting thermal simulation to advance the heat transfer analysis, showing the efficiency of the building's envelope and its components in resisting heat transfer. Moreover, discussing the comfort responses and adaptive behaviour of occupants through a post-occupancy evaluation survey would help identify challenges and suggest potential solutions to the original and rebuilt buildings.

\section{CONFLICT OF INTEREST}

The authors declare no conflict of interest.

\section{FUNDING}

No funding was received for this project.

\section{REFERENCES}

Al Haija, A. A. (2011). Jordan: Tourism and conflict with local communities. Habitat International, 35(1): 93-100.

Alzoubi, H. H., \& Almalkawi, A. T. (2019). A comparative study for the traditional and modern houses in terms of thermal comfort and energy consumption in Umm Qais city, Jordan. Journal of Ecological Engineering, 20(5): 14-22.

Bodach, S., Lang, W., \& Hamhaber, J. (2014). Climate responsive building design strategies of vernacular architecture in Nepal. Energy and Buildings, 81: 227-242.

Fernandes, J., Mateus, R., Bragança, L. and Correia da Silva, J.J., 2015. Portuguese vernacular architecture: the contribution of vernacular materials and design approaches for sustainable construction. Architectural Science Review, 58(4): 324-336.

Meier, I. A., Roaf, S. C., Gileard, I., Runsheng, T., Stavi, I., \& Mackenzie-Bennett, J. (2004). The vernacular and the Environment towards a comprehensive Research methodology. In Proc. 21st Int. Conf. on PLEA (Vol. 2, pp. 719-724). 
A Comparison Study between the Thermal Performance of the Original and Rebuilt Vernacular Buildings of Dana Village in Jordan

Nicol, F., Humphreys, M., \& Roaf, S. (2012). Adaptive thermal comfort: principles and practice. Routledge.

Philokyprou, M., Michael, A., \& Thravalou, S. (2013). Assessment of the bioclimatic elements of vernacular architecture. The historic centre of Nicosia, Cyprus. In Conference Proceedings, Le Vie dei Mercanti XI Forum Internazionale di Studi, Aversa, Capri (pp. 13-15).

Philokyprou, M., Michael, A., Malaktou, E., \& Savv- ides, A. (2017). Environmentally responsive design In Eastern Mediterranean. The case of vernacular architecture in the coastal, lowland and mountainous regions of Cyprus. Building and Environment, 111, 91-109.

Weber, W. and Yannas, S. eds., 2013. Lessons from vernacular architecture. Routledge.

https://en.climate-data.org/asia/jordan/dana/dana459275/\#temperature-graph. Retrieved June,21,2020. 